\title{
Acerca de la protección de espacios y conjuntos patrimoniales de carácter arqueo- lógico en cascos históricos de Andalucía
}

\author{
Isabel Santana Falcón*
}

\begin{abstract}
RESUMEN
Se explica el método y las conclusiones de un trabajo más amplio destinado a analizar el tratamiento otorgado al Patrimonio Arqueológico en los cascos históricos de Andalucía a partir de las figuras de protección legales y administrativas vigentes en nuestra comunidad, así como de las determinaciones del planeamiento urbanístico de cada una de las ciudades escogidas.
\end{abstract}

PALABRAS CLAVE: Patrimonio Arqueológico. Conjuntos Históricos. Cascos Históricos. Andalucía. Protección. Conservación. Planeamiento Urbanístico.

Este trabajo tuvo su origen en la convocatoria del año 2000 de las Consejerías de Obras Públicas y Cultura de la Junta de Andalucía, las cuales desarrollan de forma coordinada varias líneas de actuación para la protección e intervención en centros históricos de Andalucía !

Los proyectos propuestos para esa anualidad debían ...representar una aportación al conocimiento, caracterización y problemáticas de los centros históricos desde una perspectiva territorial, urbanística y cultural o contribuir a definir cri-

\begin{abstract}
This article discusses the methods and conclusions of a broader study designed to analyze the treatment of Archaelogical Patrimony in the historic urban sites of Andalusia using the categories for legal and administrative protection currently valid. The determinantes of urban planning used in each of the chosen cities is also examined.
\end{abstract}

KEY WORDS: Archeological Patrimony. Historical Sites. Historic Urban Sites. Andalusia. Protection, Conservation. Urban Planning.

terios y técnicas de intervención sobre el Patrimonio Histórico. En este sentido se ofertaba un bloque de temática general y otro de cuestiones específicas a cuyo epígrafe "El Patrimonio Arqueológico en los centros históricos: estudio comparado de la problemática y tratamiento de espacios o conjuntos patrimoniales de carácter arqueológico. Su conservación y difusión" se refiere este texto.

La finalidad de la investigación propuesta -confeccionar un documento de síntesis que

\footnotetext{
* Arqueóloga. Delegación Provincial en Sevilla de la Consejería de Cultura. santana-595@hotmail.com

I Orden de 4 de octubre de 2000, conjunta de las Consejerías de Obras Públicas y Transportes y de Cultura, por la que se convocan ayudas para la investigación en materias relacionadas con el Programa Regional de Planeamiento de Centros Históricos de Andalucía, BOJA núm. 122, 24 de octubre de 2000.
} 
reflejara el tratamiento otorgado al Patrimonio Arqueológico en los centros históricos de Andalucía según las diferentes figuras de protección legal y/o administrativa de las que aquél goza en los 81 conjuntos históricos declarados como Bienes de Interés Cultural y en las 53 ciudades que tienen incoados expedientes para su declaración como tal en nuestra Comunidad- implicaba la realización de una selección previa entre todas estas ciudades, sin olvidar algunas otras que no siendo conjuntos históricos declarados cuentan con elementos y restos arqueológicos de gran importancia tanto por su calidad como por su cantidad.

Además, pretendía que el trabajo tuviera vocación regional, por lo que el conjunto de poblaciones debía representar equilibradamente a todo el territorio andaluz. Entonces a cada provincia debía corresponderle un número similar de ciudades e, igualmente, debían incluirse ejemplos de todos los modelos urbanos recogidos en el Sistema de Ciudades de Andalucía?

Desde estas premisas, los centros históricos finalmente seleccionados fueron los siguientes:

- CAPITALES DE PROVINCIA: Almería, Huelva y Jaén; elegí 3 de 8 posibles;

- CENTROS SUBREGIONALES: Jerez de la Frontera; seleccioné I de 2 posibles;

- CENTROS INTERMEDIOS: Arcos de la Frontera, Úbeda, Ronda y Vélez Málaga, de las 10 posibles;

- CENTROS BÁsICOS: Montoro, Priego de Córdoba, Almuñécar, Guadix, Loja, Andújar, Carmona, Estepa y Lebrija; 9 de 33 posibles;

- CABECERAS MUNICIPALES: Cuevas del Almanzora, Vélez Rubio, Tarifa y Niebla, entre 70 posibles.
Como puede observarse, estuvieron mejor representados los centros subregionales seguidos -por este orden- de los centros intermedios y las capitales de provincia, los centros básicos y, por último, las cabeceras municipales.

Pero además, en la selección tuve también en cuenta otros motivos no menos destacables, que fueron los siguientes:

I. La relevancia del yacimiento arqueológico en estos centros históricos, según ha sido constatado en la mayoría de ellos y debe suponerse, a la luz de la documentación histórica, para aquellos donde aún no ha sido así, por ejemplo Cuevas del Almanzora o Arcos de la Frontera.

II. La entidad de los bienes del Patrimonio Histórico conservados en estos ámbitos urbanos $y$, por consiguiente, su rango en una hipotética escala patrimonial a nivel provincial, comprobándose que se escogió al menos una de las ciudades más representativas de cada provincia.

III. Fue también un elemento a considerar, en consonancia con el epígrafe anterior, el grado de desarrollo de herramientas de protección para el Patrimonio Histórico y/o Arqueológico en cada uno de los municipios. Ello permitió poner de manifiesto situaciones curiosas: por ejemplo, una población como Lebrija -que no puede competir con Carmona en cuanto a variedad y singularidad de bienes patrimoniales- aporta, en cambio, un documento urbanístico de primera magnitud para la protección de los yacimientos arqueológicos del municipio; lo mismo podría decirse de Vélez Málaga con relación a Ronda.

IV. Por último, también tuve en cuenta otros aspectos donde lo patrimonial se mezcla con lo territorial, a saber: el origen de la

\footnotetext{
2 El Sistema de ciudades de Andalucía se desarrolla en el Plan de Ordenación del Territorio de Andalucía, que puede consultarse en http://www.juntadeandalucia.es/obraspublicasytransportes/docs/urbanismo/Pota/textos/indice.pdf. Este documento es el resultado de las determinaciones del Decreto 103/1999, de 4 de mayo, por el que se aprueban las Bases y Estrategias del Plan de Ordenación del Territorio de Andalucía, el cual a su vez tuvo su origen en el Decreto 83/1995, de 28 de marzo, por el que se acuerda la formulación del Plan de Ordenación del Territorio de Andalucía.
} 
población, la relación física entre casco urbano y Conjunto Histórico y la estructura urbana del casco histórico (CONSE)ERÍA DE OBRAS PÚBLICAS Y TRANSPORTES, 200I: 15 y siguientes) ${ }^{3}$.

A continuación se enumeran estas características para las ciudades estudiadas siguiendo el orden alfabético de cada una de las provincias a que pertenecen:

- Almería. Tiene su origen en un recinto fortificado a cuyo alrededor se va desarrollando la ciudad. El Conjunto Histórico, de estructura urbana irregular, se encuentra en posición excéntrica respecto a la ciudad moderna.

- Cuevas del Almanzora (Almería). La ciudad va creciendo alrededor de un primitivo recinto fortificado. Actualmente el casco histórico, de estructura urbana algo irregular con manzanas grandes, mantiene una posición ligeramente excéntrica respecto a la ciudad.

- Vélez Rubio (Almería). Nació como punto de defensa y la ciudad creció alrededor del recinto fortificado; el Conjunto Histórico -constituido por manzanas irregulares grandes y pequeñas- se expandió a su alrededor dejando el área primitiva en el centro.

- Arcos de la Frontera (Cádiz). Su origen es un núcleo urbano alrededor de un recinto fortificado que ha ido creciendo de forma irregular, dejando el área primitiva en el centro. Conserva una estructura urbana irregular con manzanas pequeñas.

- Jerez de la Frontera (Cádiz). El origen de la ciudad, claramente medieval como puede apreciarse en la fisonomía y trazado irregular de sus calles y manzanas, debió ser un recinto fortificado que ocuparía el lugar del alcázar y unas calles a su alrededor en el entorno de la catedral. La ciudad se expandió dejando el núcleo primitivo en el centro.
- Tarifa (Cádiz). Se originó desde un recinto amurallado coincidente con el actual Conjunto Histórico, el cual mantiene una posición excéntrica respecto a la ciudad aunque inmediato a ella. Su estructura urbana es la de un recinto amurallado con manzanas pequeñas e irregulares.

- Montoro y Priego de Córdoba (Córdoba). Representan un mismo caso: un núcleo urbano alrededor de un recinto fortificado estructurado en manzanas irregulares, grandes y pequeñas. Ambas ciudades se han desarrollado de manera excéntrica pero inmediata al núcleo.

- Almuñécar (Granada). Núcleo alrededor de un recinto fortificado cuyo origen se encuentra en actividades relacionadas con el mar. El Conjunto Histórico, de estructura irregular con manzanas pequeñas, mantiene una posición ligeramente excéntrica respecto al resto de la ciudad.

- Guadix (Granada). Núcleo urbano en torno a un recinto fortificado en las cercanías de un importante cruce de caminos. El Conjunto Histórico, de estructura urbana irregular, se halla en el centro de la ciudad actual que, respecto de aquel, ha crecido de forma irregular.

- Loja (Granada). Se trata de un caso similar a Montoro y Priego de Córdoba: un núcleo urbano al pie de un cerro que crece alrededor de un recinto fortificado. El Conjunto Histórico, con un parcelario irregular de manzanas grandes y pequeñas, ocupa una posición ligeramente excéntrica respecto a la ciudad actual.

- Huelva. Nace como un enclave estratégico entre los ríos Tinto y Odiel, cercano al mar. El origen de la ciudad se encuentra en los cabezos que se distribuyen a lo largo de la costa, a partir de los cuales aquélla fue creciendo. 3 Seguí las premisas del trabajo citado, que además se toma en cuenta el tipo de emplazamiento y la forma del centro histórico aun-
que éstos parámetros parecían menos relevantes para las necesidades de nuestro trabajo. 
- Niebla (Huelva). Se emplaza, al igual que Guadix, en un importante cruce de caminos y, como Tarifa, su origen es un recinto amurallado del que se conserva su estructura urbana, coincidente con el Conjunto Histórico. Éste mantiene una posición excéntrica e inmediata respecto a la ciudad.

- Andújar (Jaén). Similar a Niebla en cuanto a su origen y a la localización del Conjunto respecto a la ciudad actual aunque, a diferencia de aquélla, su estructura urbana es irregular, con manzanas grandes y pequeñas.

- Jaén. El desarrollo urbano se produjo a los pies del castillo, ocupando la falda del cerro en que se ubica, a partir de un núcleo inicial de población en la zona más alta de la ciudad. El Conjunto Histórico se encuentra en posición excéntrica respecto a la ciudad y se caracteriza por un parcelario variado que incluye pequeñas manzanas irregulares y sectores con una ordenación más racional en parcelas mayores.

- Úbeda (Jaén). Se trata de un núcleo urbano que crece alrededor de un recinto fortificado construido en un importante cruce de caminos. El Conjunto Histórico, con una estructura urbana irregular de manzanas pequeñas, se sitúa excéntrico a la ciudad e inmediato a ella.

- Ronda (Málaga). Al igual que Úbeda, Niebla o Andújar se trata de un núcleo urbano en un importante cruce de caminos. El recinto amurallado coincide con el núcleo histórico, excéntrico respecto a la ciudad actual. Su estructura urbana es algo irregular predominando las manzanas pequeñas.

- Vélez Málaga (Málaga). El núcleo urbano se originó al pie de un cerro con una posición fortificada, en un cruce de caminos. El Conjunto Histórico, excéntrico respecto a la ciudad está junto a ella; mantiene una estructura irregular de manzanas pequeñas.

- Carmona (Sevilla). Al igual que Niebla, Ronda y Tarifa, el recinto amurallado origen de la ciudad coincide con el Conjunto Histórico, ocupando una posición excéntrica e inmediata al núcleo urbano. El parcelario está formado por manzanas irregulares pequeñas.

- Estepa (Sevilla). Similar a Vélez Málaga en cuanto a su emplazamiento -al pie de un camino principal- y ubicación, en un cerro con una posición fortificada. El Conjunto Histórico, de estructura irregular, ocupa una posición ligeramente excéntrica respecto a la ciudad actual.

- Lebrija (Sevilla). Igual que Estepa, con la salvedad de que se encuentra más alejado de una vía de comunicación principal.

Como es fácil imaginar, se trataron centros históricos de todas las dimensiones, oscilando entre las aproximadamente $15 \mathrm{Has}$. de Arcos de la Frontera y Tarifa y las 105 Has. de Carmona y casi 100 Has. de Ronda donde, si se tiene en cuenta la zona de respeto del Conjunto Histórico, su superficie se triplica ${ }^{4}$.

Y, por supuesto, las dimensiones de los yacimientos arqueológicos bajo suelo urbano son también variadas. Partiendo del hecho de que bajo una ciudad subyace un único yacimiento, independientemente de las distintas fases de ocupación que puedan documentarse y de su continuidad cronológica o espacial ${ }^{5}$, las ciudades estudiadas albergan toda una tipología de sitios arqueológicos:

- ciudades donde el origen del poblamiento se ha constatado, a través de sucesivas excavaciones arqueológicas, en el II-III milenio a.C. y han conservado restos de todas las épocas: Guadix, Huelva, Jaén, Ronda o Carmona;

\footnotetext{
4 En el trabajo citado, ibid supra, se recogen las dimensiones de todos los Conjuntos Históricos de ciudades medias y pequeñas de Andalucía.

5 La continuidad y consistencia de los restos arqueológicos subyacentes es casi siempre directamente proporcional, o en todo caso superior, a la que puede detectarse formando parte de los antiguos inmuebles, a veces bajo innumerables capas de acabados, y no sólo en edificios de carácter monumental sino también en el caserío tradicional.
} 
- otras donde la ocupación se originó y creció durante el I milenio a. C. y fue más que notable en época romana: Montoro, Almuñécar y Estepa;

- las que fueron importantes centros defensivos desde la Alta Edad Media y han mantenido su carácter urbano: Tarifa o Niebla;

- enclaves territoriales de entidad constatados desde la Alta Edad Media: Almería, Jerez de la Frontera y Úbeda -en menor escala Priego de Córdoba y Andújar- cuyos orígenes son anteriores -romanos en el caso de Almería, protohistóricos en Úbeda-;

- ciudades que nacieron o tuvieron su mayor desarrollo a partir de la conquista cristiana: Vélez Málaga;

- centros urbanos de los que sólo conocemos parcialmente su desarrollo histórico, pero donde se han constatado restos desde la Prehistoria: Loja y Lebrija;

- una ciudad creada ex novo en época moderna -siglo XVI-: Vélez Rubio;

- y, por último, aquellas ciudades de las que no encontré información arqueológica más allá de noticias históricas y estudios locales pero que deben conservar vestigios arqueológicos relevantes: Cuevas del Almanzora y Arcos de la Frontera.

Este era, muy sintéticamente, el panorama territorial y arqueológico-patrimonial de las ciu- dades sobre las que desarrollaría el trabajo. Y en esa realidad era necesario valorar las medidas de protección para los yacimientos arqueológicos, las cuales procedían de dos fuentes:

- las figuras de protección contempladas en las leyes I//99| PHA y 16/1985 PHE: Zonas de Servidumbre Arqueológica, inscripciones específicas y genéricas en el Catálogo General del Patrimonio Histórico de Andalucía y declaraciones como Zonas Arqueológicas Bien de Interés Cultural;

- y el planeamiento urbanístico.

Sólo en tres casos se habían desarrollado instrumentos legales de protección para yacimientos arqueológicos bajo suelo urbano ${ }^{6}$. Sin embargo, como se supondrá, todas los municipios contaban con planes urbanísticos y éstos, en mayor o menor medida, contemplaban la preservación de los bienes culturales ${ }^{7}$.

También debía considerar las normas específicas para la protección del Patrimonio Arqueológico desarrolladas en Andalucía desde el Programa de Cartas Arqueológicas iniciado en 1998, del que ya se han concluido los documentos de Priego de Córdoba, Guadix, Niebla, Úbeda, Carmona y Lebrija, en lo que se refiere a los municipios objeto de este trabajo ${ }^{8}$.

Por último, parecía necesario examinar otros expedientes administrativos, como los estudios de diagnóstico para la declaración como Bien de Interés Cultural de algunos conjuntos his-

6 Me refiero a las inscripciones con carácter específico en el Catálogo General del Patrimonio Histórico Andaluz del Casco Urbano de Huelva (Orden de 14 de mayo de 200I, por la que se inscribe específicamente en el Catálogo General del Patrimonio Histórico Andaluz la Zona Arqueológica de Huelva, BOJA n I3I de II de noviembre de 1999, cuyo precedente es el Decreto I90/I992 por el que se declara Bien de Interés Cultural la Zona Arqueológica del Cabezo de San Pedro, BOJA n I, I5 de enero de I993) y del yacimiento arqueológico de Marroquíes Bajos en Jaén (Resolución de 8 de mayo de 2002, de la Dirección General de Bienes Culturales, por la que se incoa procedimiento para la inscripción con carácter específico en el C.G.P.H.A. como Zona Arqueológica Bien de Interés Cultural del yacimiento Marroquíes Bajos, en Jaén -BOJA n 68, II de junio de 2002-, cuyo precedente fue la Orden de 7 de julio de 1997 por la que se resolvía inscribir con carácter específico en el C.G.P.H.A., con la categoría de Zona Arqueológica, el yacimiento Marroquíes Bajos, en Jaén -BOJA n 96, 16 de agosto de 1997-, incoado mediante Resolución de fecha 13 de junio de 1995); y, por último, a la declaración como BIC del Conjunto Histórico de Almería (Decreto 107/|999, por el que se declara y delimita como Bien de Interés Cultural el Conjunto Histórico de Almería, BOE n 167, 14 de julio de 1999), que incluye el yacimiento arqueológico subyacente.

7 Como se ha demostrado, el planeamiento urbanístico es una excelente herramienta para instrumentar la protección de los bienes del Patrimonio Histórico, tal y como reconoce la propia Ley 16/I985 PHE y desarrolla la Ley I/I99| PHA y, por lo tanto, sus determinaciones pueden, y deben, ser complementarias de las medidas legales de protección.

8 Actualmente se están elaborando, entre otras, las cartas arqueológicas de Jerez de la Frontera, Montoro, Almuñécar, Loja y Ronda. 
tóricos que, incluso cuando aún no se han materializado en una figura de protección específica, ofrecen datos valiosos.

Como resultado del análisis de todas estas variables establecí unas primeras proposiciones de carácter general relativas a la gestión del Patrimonio Arqueológico urbano en Andalucía:

I. El grado real de protección de los yacimientos arqueológicos en suelo urbano a partir de las determinaciones del planeamiento urbanístico es casi tan variado como lo son los documentos urbanísticos examinados. Como se verá más adelante a través de la explicación de casos concretos y posteriormente en las conclusiones, no siempre es suficiente con la introducción de medidas protectoras en el planeamiento, sobre todo si no se toman en cuenta aspectos tan decisivos para la preservación de los yacimientos arqueológicos como la calificación, clasificación y usos del suelo que se pretende proteger. $Y$ no siempre se desarrolla una normativa de protección para el Patrimonio Arqueológico; ni en planes generales ni, a veces, en planes especiales redactados para compatibilizar el crecimiento urbano con la preservación del Patrimonio Histórico.

2. Las medidas de protección hasta ahora mayoritariamente adoptadas frente el desarrollo urbanístico no pueden considerarse suficientes por sí solas para garantizar la correcta gestión de los yacimientos en suelo urbano porque se han limitado casi exclusivamente a la excavación arqueológica de urgencia para superar la destrucción indiscriminada de los restos arqueológicos.

3. Y, como consecuencia de la supeditación de la excavación arqueológica al hecho urbanístico -que no debemos aceptar como único camino para la preservación del yacimiento a la vista de las múltiples y variadas soluciones que se pueden incardinar en el planeamiento-, la responsabilidad de ejecutar las intervenciones arqueológicas ha devenido casi exclusivamente en manos de particulares o de otras administraciones, que han de asumirlas en función de los preceptos legales ${ }^{\text {? }}$.

4. Sin embargo, la Consejería de Cultura no ha asignado hasta ahora una partida presupuestaria, o creado un programa específico, para el estudio de contextos, bienes y elementos arqueológicos recuperados en el curso de esas intervenciones, tramitadas como excavaciones de urgencia aunque en muchas ocasiones se hayan convertido en verdaderas actuaciones sistemáticas, al menos en lo que a actuación sobre un sitio arqueológico se refiere.

5. Por lo tanto, no existe un programa de investigación arqueológica en cascos urbanos, ni de difusión de resultados de las intervenciones arqueológicas realizadas -excepto la publicación periódica del Anuario Arqueológico de Andalucía, desde el año 1985-, aunque el Programa de Cartas Arqueológicas Municipales de los Servicios de Protección e Investigación de la Dirección General de Bienes Culturales ha de entenderse como un paso importante en ambos sentidos que poco a poco empieza a dar sus frutos (RODRÍGUEZ DE GUZMÁN SÁNCHEZ, Sandra; GONZÁLEZ-CAMPOS BAEZA, Yolanda, 2002. RODRÍGUEZ TEMIÑO, Ignacio; RODRÍGUEZ DE GUZMÁN SÁNCHEZ, Sandra, 1997) ${ }^{10}$.

En cualquier caso, estas primeras reflexiones tienen un desarrollo particular casi para cada una de las veintiún ciudades estudiadas. Por lo tanto, para ilustrar esta exposición me

\footnotetext{
9 Decreto 19/1995, de 7 de febrero, por el que se aprueba el Reglamento de Fomento y Protección del Patrimonio Histórico de Andalucía, BOJA núm. 43, de 17 de marzo, Artículo 48. Régimen de autorizaciones en áreas que cuenten con protección arqueológica.

10 Además, el nuevo Reglamento de Actividades Arqueológicas contempla la promoción, por parte de la Consejería de Cultura, de un Programa General de Investigación de estas características; véase el Decreto 168/2003, de 17 de junio, por el que se aprueba el Reglamento de Actividades Arqueológicas, BOJA núm. 134 de 15 de julio de 2003, artículo I 4 y siguientes.
} 
centraré en tres ejemplos concretos: Jerez de la Frontera (Cádiz); Úbeda (Jaén) y Lebrija (Sevilla).

Aunque estos municipios poseen diferente rango territorial en el sistema de ciudades de Andalucía -centro subregional, centro intermedio y centro básico, respectivamente- son referentes de primer orden para cada una de sus provincias. Además, desde el punto de vista urbanístico, los tres cuentan con planes generales de reciente formulación que desarrollan normas específicas para la protección del Patrimonio Arqueológico urbano, aunque de muy distinta profundidad y alcance como tendremos oportunidad de ver a continuación. En todos los casos han redactado, o lo están haciendo en la actualidad, Planes Especiales de Protección para el Conjunto Histórico o sectores concretos del mismo. Úbeda tiene concluida la Carta Arqueológica, la de Jerez se encuentra en redacción y Lebrija ha materializado el análisis histórico-arqueológico-urbanístico del casco urbano en unas normas para la protección del yacimiento arqueológico incluidas en la Normas Urbanísticas del propio Plan General.

El casco antiguo de Jerez de la Frontera fue declarado Conjunto Histórico-Artístico según el Decreto 1390//982 de 17 de abril 'I. El documento urbanístico que tiene en vigor es un Plan General de Ordenación Urbana aprobado definitivamente el 22 de marzo de $1995^{\text {12; }}$ desde esa fecha se han producido doce modificaciones -incluida la publicación de Normas Urbanísticas ${ }^{13}$ - afectando sólo una de ellas al Conjunto Histórico ${ }^{14}$.
Tras la aprobación del PGOU se redactó un Plan Especial de Protección para los sectores de Belén y Benavente ${ }^{15}$, incluyendo éste algunas consideraciones de índole arqueológica debido a la existencia de restos medievales -almohades concretamente- en la zona, aunque las excavaciones hasta ese momento habían sido muy escasas ${ }^{16}$. Desde la entrada en vigor del plan especial los solares que vayan a ser vaciados y/o aquellos donde se estimen posibilidades para la investigación serán objeto de actuaciones arqueológicas. Como primer paso para estas actuaciones debería redactarse un catálogo de inmuebles que recoja y valore el potencial arqueológico de cada uno de ellos en función de los elementos, estructuras y contextos conservados; en atención a estos parámetros se propondrá la declaración de Zonas de Servidumbre Arqueológica al amparo del artículo 48 de la Ley I/I99| PHA.

Respecto a las cuestiones puramente arqueológicas, el Ayuntamiento, mediante convenio con la Consejería de Cultura, ha iniciado los trabajos de realización de la Carta Arqueológica Municipal ${ }^{17}$.

En otro orden de cosas, el Ayuntamiento ha difundido en la publicación electrónica Ayuntamiento en Marcha el documento "Salvar el Centro", que explica ...una estrategia global y única para la recuperación del Casco Histórico desarrollada mediante el Plan Integral del Centro Histórico, que cuenta con ocho ejes de actuación que serían asumidos por la Agencia [Municipal] del Centro Histórico ${ }^{18}$.

\footnotetext{
II BOE n $|5|$ de 25 de junio de 1982.

12 El documento examinado fue el Texto Refundido: Jerez, Plan General Municipal de Ordenación Urbana, Consejería de Obras Públicas y Transportes de la Junta de Andalucía y Ayuntamiento de Jerez, Sevilla, 1998, versión en CD-ROM.

13 Modificación n 10, Normas Complementarias del Suelo Urbano, Boletín Oficial de la Provincia del I4 de junio de 200I. Según el Inventario de Planeamiento Urbanístico de la Consejería de Obras Públicas de la Junta de Andalucía.

14 Subsanación de errores, que se publicó en el Boletín Oficial de la Provincia de Cádiz de 30 de noviembre de I999. Según el Inventario de Planeamiento Urbanístico de la Consejería de Obras Públicas de la Junta de Andalucía.

15 PERI Belén-Benavente aprobado definitivamente el 29 de mayo de 1998, BOJA de 3 de julio de 1998.

16 Así puede inferirse de lo hasta ahora publicado en el Anuario Arqueológico de Andalucía, publicación oficial de la Consejería de Cultura

17 Según información de la publicación electrónica http://www.webjerez.com/ciudad/consistorio/jul_02/noticia4.asp, confirmada por la Dirección General de Bienes Culturales.

18 http://www.webjerez.com/ciudad/consistorio/oct_02/noticia4.asp.
} 
Aunque estas iniciativas municipales de salvaguarda del Patrimonio Histórico resultan muy interesantes y en algunos aspectos novedosas si las comparamos con otras localidades de entidad analizadas, sin embargo podríamos esperar algunas debilidades para la salvaguarda del patrimonio arqueológico debido a la escasa consistencia de las determinaciones de protección recogidas en el Plan General para el yacimiento arqueológico en suelo urbano.

Para empezar, el P.G.O.U incluye el Patrimonio Arqueológico del Conjunto Histórico en el epígrafe Zona de Protección Arqueológica, es decir: ...áreas susceptibles de ser estudiadas con metodología arqueológica, y que requieren de un régimen cautelar que preserve el interés público. A pesar de ello, se someten al régimen jurídico establecido en función de una clasificación y calificación estrictamente urbanísticas.

En estos casos, los servicios municipales competentes en materia arqueológica informan la solicitud de licencia de obras, y si se determina la necesidad de acometer actuaciones arqueológicas previas ...la resolución aprobatoria del proyecto incorporará cláusula expresa de suspensión por un mes del plazo del inicio de las obras; si la suspensión se prolongase, la Consejería de Cultura se verá ...obligada a resarcir el daño efectivo que se causara con tal paralización. Cuando sea necesario realizar una intervención arqueológica, el promotor deberá informar de tal extremo al Servicio Arqueológico Municipal ...quién estará facultado para inspeccionar en todo momento las obras. (Artículos 29I, 292 y 293, Título III. De las normas particulares del SNU).

Por otra parte, las Normas Particulares del Suelo Urbano y Urbanizable califican como Zonas de Servidumbre Arqueológica...aquellas parcelas catastrales del Conjunto Histórico de Jerez que estén afectadas por la cerca almohade de la ciudad (artículo 374), siéndoles de aplicación las normas antes citadas. Las obras en los lienzos de muralla o torreones deben ser autorizadas por la Gerencia Municipal de Urbanismo y ajustarse a lo establecido para los edificios de interés específico en el artículo 368.

Hasta aquí las medidas de preservación del Patrimonio Arqueológico en el Plan General porque éste, basándose en una serie de consideraciones que a continuación veremos sobre el planeamiento urbanístico como instrumento para la preservación del Patrimonio Histórico, consigue eludir un aspecto tan crucial para la ordenación urbana como es el tratamiento de los bienes arqueológicos, lo que no se comprende en un planeamiento de carácter general para una ciudad de la entidad patrimonial de Jerez.

Así, podemos leer:

La preservación de la arquitectura urbana es una acción normativa global y operativa. Debe distinguirse de la localización de restos y su protección como labor erudita de investigación especializada. El valor historiográfico de las collaciones o la ubicación de usos desaparecidos que no han dejado huella material pertenecen a otro campo de actividad.

...El Plan General de Ordenación Urbana aborda una realidad con la cual debe operar, dosificando el peso de la historia. Para ello, en cada caso y mediante la lógica del proyecto arquitectónico, deberá determinarse la protección requerida, en vez de utilizar normativas genéricas, como es el caso de los usuales niveles de protección...

...La función predictiva del Plan debe realizarse de diversa manera. La información debe facultar para descartar aquello que es susceptible de renovación, de aquello otro que presumiblemente es valioso y por tanto inalterable. La profundización y estudio de lo que es valioso se considera como una actividad académica fuera del ámbito del Plan ${ }^{19}$.

19 Síntesis del Análisis Urbanístico. Diagnóstico, I.7. Diagnóstico e interpretación del Centro. 
He entresacado estos tres párrafos como hilo argumental de un discurso que, basándose en la innegable necesidad de que las ciudades en general y los conjuntos históricos en particular deben ser modificados y renovados para adaptarse al ritmo de los tiempos, pone en crisis la inclusión de medidas de preservación del Patrimonio Histórico en el planeamiento urbanístico, concluyendo lo siguiente:

En definitiva, el Plan General de Ordenación Urbana, en su acción ordenadora, propone un modelo de ciudad revisado y que en el caso del Conjunto Histórico debe tener en cuenta las leyes de patrimonio, pero no al revés.

Si el revés se refiere a que las medidas relativas a la preservación del Patrimonio Histórico no deben ser determinantes en el modelo de ciudad que finalmente proponga el Plan, estoy en líneas generales de acuerdo. Y, de hecho, creo que las normas de protección que habitualmente se recogen en los documentos de planeamiento no tienen esas pretensiones; aunque sí intentan que dicho modelo no se sustancie únicamente en la idea de ciudad que manifiesta el equipo redactor -repentinamente sublimado en el término el Plan por mor del consenso social que supone la aprobación de un documento urbanístico-, sobre todo si esa idea no toma lo suficiente en consideración aquello que es reconocido por sus valores culturales y debe ser, por tanto, indudablemente protegido.

Tampoco encuentro justificada la función predictiva (?) del Plan, que supongo se referirá al Plan como instrumento de predicción, para dilucidar -trascendiendo aspectos puramente arquitectónicos y/o urbanísticos- entre lo que es histórica, arqueológica o, en general, culturalmente valioso. Porque para evaluar esas categorías, si bien no es imprescindible la labor erudita de investigación especializada, sí es necesario implicar a profesionales cualificados en esos campos $y$, por supuesto, con experiencia en redacción de documentos urbanísticos. Y así puede hacerse evidente cómo el valor histórico (que no historiográfico) de las collaciones se mantiene, por ejemplo, en el trazado de sus calles, en la configuración actual de su parce- lario y, en algunos casos, en elementos arquitectónicos aún observables a través de un análisis arqueológico de lo construido.

Por último, no creo que un Plan General deba abordar la realidad a la que se enfrenta dosificando el peso de la historia. Por dos motivos: primero, porque de ser así no se está enfrentando a la realidad: no se dosifica -creo- el peso de los espacios naturales o de las infraestructuras; y segundo, porque se trata de la Historia, o sea el conjunto de elementos materiales e inmateriales de todos los tipos y todas las épocas que han dado forma a la ciudad sobre la que trata el documento. Así, es tan importante proteger la arquitectura y el ambiente urbano de las bodegas jerezanas -que tan detalladamente analiza como bien resuelve el PGOU - como los restos arqueológicos que puedan conservarse en el subsuelo y en las edificaciones históricas de Jerez. Y, probablemente, el mismo catálogo que se confeccionó para la arquitectura serviría también para aquel cometido si un arqueólogo hubiera diseñado e incluido los campos necesarios.

Y todo este trabajo, insisto, está alejado de la labor erudita de un científico o investigador especializado. El quid de la cuestión, desde mi punto de vista, reside en contar con los profesionales indicados $y$, sobre todo, en no partir de ningún a priori respecto a otras disciplinas que, como se demuestra cada vez más necesario, deben participar en la redacción de un documento urbanístico.

El centro histórico de Úbeda fue declarado Conjunto Histórico mediante Decreto de 4 de febrero de 1955. Sus límites comprenden el recinto amurallado más un área de respeto de $100 \mathrm{~m}$ de ancho a su alrededor.

El planeamiento municipal vigente lo conforman un Plan General de Ordenación Urbana que fue definitivamente aprobado en diciembre de 1996 y un Plan Especial de Protección del Conjunto Histórico, aprobado en 1989 y posteriormente convalidado por la Consejería de Cultura. Este último cuenta con un Catálogo que asigna varios grados de protección a los inmuebles de carácter histórico e incluye con- 
tenido específico de protección para el yacimiento arqueológico.

El Plan General hace suyas las determinaciones del PEP, al que se remite para las cuestiones relacionadas con la protección del Patrimonio Histórico en su ámbito de actuación.

Durante los años 1999 y 2000 la Universidad de Jaén redactó la Carta de Riesgo Arqueológico de la Ciudad de Úbeda, subvencionada por la Consejería de Cultura a través del Ayuntamiento de Úbeda (SALVATIERRA CUENCA, Vicente; GARCÍA GRANADOS, Juan, 2000). Se trata de un estudio específico dedicado a la protección del Patrimonio Arqueológico urbano que incluye un análisis y una valoración a mi parecer bastante acertados sobre la eficacia de las medidas de protección en el planeamiento vigente en la ciudad.

La carta arqueológica, partiendo de los datos obtenidos desde la documentación histórica, realiza un exhaustivo análisis del urbanismo de la ciudad incluida en el recinto amurallado, incluyendo las parcelas exteriores inmediatas a la muralla y las superpuestas a ella, para terminar avanzando una propuesta de zonificación arqueológica sensiblemente diferente a la asumida por el Plan Especial.

La nueva propuesta reduce las siete zonas y subzonas de protección del PEP a cinco, con diferentes grados de protección ${ }^{20}$. Tales diferencias obedecen a distintas manera de entender la investigación en arqueología urbana: mientras que en el Plan Especial se construyó un documento teórico basado en posibles líneas e hipótesis de trabajo, en la Carta Arqueológica los datos, noticias e hipótesis de carácter puramente histórico se imbrican con la realidad urbanística de la ciudad.
De este modo, a la hora de establecer ámbitos de protección no sólo se valora el dato o la noticia histórica sino también la posibilidad de localizar elementos arqueológicos dentro de la trama actual ${ }^{21}$, así como la ausencia de conocimiento en determinados períodos, los cuales pueden suponerse enmascarados por la propia dinámica de desarrollo y evolución urbana. Se concluye, en consecuencia, la necesidad de practicar, además de arqueología vertical -paramental y/o subyacente-, excavaciones en extensión en los ámbitos que resultan más propicios según el doble análisis realizado.

Se alcanza así una propuesta de normativa de intervención con un carácter marcadamente espacial, en el sentido de que se apoya en los distintos tipos de ámbitos que se han detectado intramuros de la ciudad, a saber: interior de parcelas, espacios públicos, perímetro de muralla y espacios no urbanizados. A partir de ellos se desarrollan cinco tipos de actuación: diagnóstico histórico-arqueológico, como actuación previa a la licencia de obra 22; análisis de la estratigrafía muraria, en edificaciones históricas hasta el siglo XVII y las consideradas tradicionales donde se constate superposición de estructuras; excavación sistemática, en todas las parcelas del interior del recinto amurallado; sondeos estratigráficos, al exterior de la muralla en las zonas colindantes con la misma; control de movimientos de tierra, en áreas perimetrales no urbanizadas.

Todas estas zonas se someten a un volumen de excavación que oscila entre un mínimo obligatorio de $50 \mathrm{~m}^{2}$, en parcelas inferiores a $150 \mathrm{~m}^{2}$, y $75 \mathrm{~m}^{2}$ para las que superen aquellas dimensiones. En parcelas mayores de $500 \mathrm{~m}^{2}$ el ámbito de excavación estará sujeto a la edificabilidad permitida por el Plan Especial.

\footnotetext{
20 En el PEP las áreas de protección se desarrollan de manera radial desde el recinto del alcázar hasta el exterior del recinto amurallado - barrios de San Isidoro y San Nicolás, al norte y oeste; Los Sanjuanes, Arrabal de San Millán y alfares de la calle Valencia, al este- y se resuelven mediante tres niveles de protección. En la Carta Arqueológica las zonas de especial interés presentan una evidente discontinuidad física en los niveles I (de máximo interés arqueológico) y 2 (de alto interés arqueológico), y para la totalidad del área estudiada se contemplan cuatro niveles de protección.

2 Illo obedece en buena medida a la escasez de excavaciones arqueológicas en el casco urbano, que se suplió con un análisis puramente urbanístico del parcelario para el que se observaron cuatro parámetros: cronología de la edificación, amplitud de los espacios libres internos, densidad de edificios catalogados y estado de conservación de los inmuebles.

22 Se recoge también en el Plan Especial como informe histórico-arqueológico.
} 
Hasta aquí las determinaciones de la Carta Arqueológica de Úbeda, sin duda uno de los documentos de protección del yacimiento arqueológico urbano más exhaustivo y riguroso de los analizados en lo que a fundamentos metodológicos se refiere.

Otra cuestión es la gestión propiamente dicha del documento que, en mi opinión, tropieza con dos inconvenientes fundamentales:

I. La Carta Arqueológica, por ahora, no es un documento con carácter normativo. Que yo sepa, sus determinaciones no han sido aún asumidas por el planeamiento urbanístico, lo que significa que posiblemente sigan aplicándose las normas recogidas en el Plan Especial. Esta situación puede representar, para determinadas zonas del Conjunto Histórico, una desventaja en cuanto a la posibilidad de recuperar información históricoarqueológica.

2. Para una aplicación eficaz de este documento sería necesario desarrollar algunas cuestiones no suficientemente tratadas en él:

a) una Normativa de Procedimiento donde se especifique la necesidad de que las excavaciones arqueológicas sean ejecutadas por técnicos competentes en esta materia, los cuales deberán aportar garantías en orden a la ejecución de las obras que, por motivo de la intervención arqueológica, sea necesario realizar. Dicha normativa debe establecer igualmente en qué persona, física o jurídica, recaerá la financiación de las intervenciones arqueológicas, a tenor de lo dispuesto en la legislación autonómica vigente;

b) un capítulo destinado a desarrollar Criterios de Conservación y Puesta en Valor de Elementos Arqueológicos, con sus correspondientes normas, para el caso de que surgieran restos merecedores de ello. Lo cual no parece difícil según el resultado del análisis histórico y urbanístico realizado y según puede esperarse de actuaciones a desarrollar a medio plazo, como la ejecución del Plan Especial de Reforma Interior de las Eras del Alcázar. c) un capítulo para establecer el Régimen de Ayudas y Subvenciones para actividades relacionadas con la preservación del Patrimonio Histórico de índole arqueológico, especialmente en aquellas zonas consideradas Áreas de Rehabilitación Preferente.

Para finalizar, resulta preocupante, a tenor de la documentación consultada, el escaso número de intervenciones arqueológicas realizadas en el Conjunto Histórico de Úbeda, como ya se puso de manifiesto en la carta arqueológica. No parece que en los últimos tiempos esta situación se haya modificado o, por lo menos, no he encontrado nuevas publicaciones sobre la ciudad. $Y$ esta es una tendencia que debería ser rápidamente contrarrestada, y no precisamente mediante la aplicación de la Carta de Riesgo sino a través de la propia Comisión Provincial de Patrimonio Histórico de Jaén. Aunque no examiné los archivos del citado Organismo, es un hecho que de dieciocho intervenciones arqueológicas acometidas en la ciudad sólo tres se han resuelto con excavaciones, siendo los restantes informes arqueológicos aún cuando al menos en otras tres ocasiones se trata de solares afectados por elementos defensivos y lienzos de muralla (SALVATIERRA CUENCA, Vicente; GARCÍA GRANADOS, Juan, 2000: 86).

Por todo lo dicho, podemos concluir que la Carta de Riesgo Arqueológico de Úbeda resulta un excelente comienzo para otras actuaciones preventivas que en su desarrollo habrán de venir en un futuro seguramente cercano.

Lebrija tiene actualmente en vigor unas Normas Subsidiarias que fueron aprobadas definitivamente el 20 de diciembre de 1985, publicándose el 30 de abril de 1986 el Catálogo de inmuebles protegidos. Asimismo, en el Boletín Oficial de la Provincia de Sevilla de 12 de junio de 200 I se encuentran las Normas Urbanísticas del nuevo Plan General de Ordenación Urbana aunque, según las noticias recabadas en la página digital de la Consejería de Obras Públicas, dicho documento no ha sido aún sometido a aprobación definitiva. 
El casco antiguo de Lebrija, en base a sus valores patrimoniales y al estado de conservación de su estructura urbana original así como otras características arquitectónicas propias, fue declarado Conjunto Histórico mediante el Decreto 14/1985, de 22 de enero ${ }^{23}$.

No obstante, el yacimiento urbano nebrisense ha sido hasta hace escasamente cinco años bastante desconocido, aunque en dos ocasiones se realizaron excavaciones arqueológicas cuyos resultados permitían suponer la existencia de restos arqueológicos de interés (CARO BELLIDO, Antonio; ACOSTA MARTíNEZ, Pilar; ESCACENA CARRASCO, José L., 1987) ${ }^{24}$.

Entre 1998 y 2000 también se han llevado a cabo excavaciones en el recinto fortificado y en la iglesia de Santa María del Castillo -aún pendientes de publicación- que constataron la ocupación de la zona desde la Protohistoria, así como distintas fases constructivas y de uso del recinto fortificado, además de analizar arqueológicamente la iglesia, aportando abundantes y novedosos datos al proyecto de restauración.

De los interesantes resultados de esas actuaciones se dedujo la necesidad de profundizar en el análisis arqueológico del casco urbano para, aprovechando la oportunidad que suponía la redacción de un nuevo documento urbanístico, incluir medidas específicas de cara la protección del yacimiento subyacente. Dicho trabajo, auspiciado por un convenio entre la Consejería de Cultura y el Ayuntamiento, tomó como punto de partida no sólo el análisis de la documentación histórica y arqueológica sino también del parcelario y la morfología urbana, para concluir en el establecimiento de tres niveles de protección:

- Grado I. Nivel máximo de protección. Implica la documentación e investigación exhaustiva de toda afección al subsuelo en el área comprendida bajo este epígrafe. El método empleado será la excavación arqueológica en extensión, cuyos porcentajes también se detallan.

- Grado 2. En la zona así delimitada se debe documentar la secuencia estratigráfica y ...obtener información general que permita acceder a la evolución histórica del solar. El método empleado será el de excavación arqueológica puntual que, al menos en un sector de la parcela, debe agotar la estratigrafía histórica.

- Grado 3. En el suelo urbano bajo esta protección será necesario llevar a cabo un control arqueológico en el curso de los movimientos de tierra. El hallazgo de restos de especial interés inducirá el cambio del nivel de protección a uno superior, según la naturaleza y relevancia de los restos. Lo mismo se prevé para el Grado 2 respecto del Grado I.

Asimismo, se reconocen dos niveles de protección para el patrimonio emergente:

- Grado I. Edificios históricos protegidos; inmuebles parcialmente conservados en otras edificaciones; inmuebles o edificaciones singulares de interés arqueológico.

- Grado 2. Inmuebles que colindan o se adosan a restos defensivos emergentes.

Todas las obras de consolidación y restauración -Grado 2- así como las de rehabilitación, demolición parcial y nueva planta -Grado I- a realizar en inmuebles de las características citadas están sujetas a previa realización de intervenciones arqueológicas, cuya metodología se detalla con precisión en ambos casos.

Se desarrolla igualmente un capítulo muy interesante -del que sólo encontramos similitudes en la Carta Arqueológica de Priego de Córdoba- dedicado a los criterios de conser-

\footnotetext{
23 BOJA 22 de febrero de 1985.

24 La excavación documentó una secuencia de ocupación que se iniciaba en momentos iniciales del Neolítico, continuando casi sin interrupción hasta la actualidad.
} 
vación de restos arqueológicos. Dichos criterios se basan en tres principios: la singularidad y relevancia del conjunto exhumado, su estado de conservación y su capacidad para transmitir valores culturales a un público no especialista, valorándose complementariamente el uso previsto para la parcela.

Las actuaciones de conservación, por su parte, se presentan bajo tres modalidades: conservación e integración del conjunto, conservación bajo cimentación y extracción puntual de elementos arqueológicos notables.

Para concluir, se trata también el procedimiento administrativo de concesión de licencias urbanísticas para todas aquellas obras que necesiten intervenciones arqueológicas previas y/o simultáneas a su ejecución, estableciéndose la obligación de realizarlas y costearlas por parte del promotor y condicionando la obtención de la licencia urbanística al desarrollo de la intervención arqueológica.

Toda esta batería de medidas está dando ya óptimos resultados. Así, la excavación arqueológica en la nueva sede de la Casa de la Cultura ha recuperado una serie de estructuras romanas -una cloaca, una calle y parte de las casas anejas- que están siendo sometidas a labores de conservación y puesta en valor para ser integradas en el edificio.

Por otra parte, los controles de los movimientos de tierra realizados en algunos inmuebles de la zona bajo protección 3 -donde nunca antes se habían hecho excavaciones arqueológicas- han permitido documentar interesantes restos arqueológicos protohistóricos que parecen aconsejar, para alguna zona en concreto, el cambio de cautela al nivel inmediatamente superior.

Y todo esto en los dos años que llevan en vigor las Normas Urbanísticas.

De este modo, Lebrija se ha convertido en un ejemplo evidente de la utilidad de una normativa de protección del Patrimonio Arqueológico para la gestión del yacimiento, y por consiguiente del suelo urbano, elaborada a partir de un análisis arqueológico simultáneo a la nueva formulación, revisión o modificación de un documento de planeamiento, e introduciendo los trabajos arqueológicos en el proceso de redacción del Plan General.

Hasta aquí tres ejemplos de lo que a nivel particular dio de sí el estudio de la documentación. Pero, además, el análisis conjunto de todos los casos estudiados me permitió plantear algunas valoraciones de índole general respecto a la gestión del Patrimonio Arqueológico urbano en Andalucía, a saber:

I. Existe un nivel casi homogéneo de protección en cuanto al uso de herramientas legales y urbanísticas: cuando la protección no se basa en una declaración de Conjunto Histórico que luego se desarrolla mediante un Plan Especial, se consigue introduciendo normativa específica en el planeamiento general, como sucede en Jerez, Tarifa o Guadix. En ocasiones se dan todas estas circunstancias, por ejemplo en Jaén, Vélez Rubio, Arcos de la Frontera y Vélez Málaga.

Constituyen un caso similar las ciudades de Almería y Huelva. La primera posee un Plan General con contenido de protección para el Patrimonio Arqueológico y tiene declarado el Conjunto Histórico, incluyendo el yacimiento arqueológico, como BIC. En Huelva, el PGOU recoge medidas para la protección de los yacimientos arqueológicos y la Zona Arqueológica de Huelva ha sido inscrita con carácter específico en el Catálogo General del Patrimonio Histórico de Andalucía.

La excepción la representan los municipios de Cuevas del Almanzora, con un expediente de protección que no ha concluido su tramitación; Almuñécar, con un Plan General obsoleto y sin contenido de protección, un Informe Diagnóstico del Conjunto Histórico que no ha concluido en declaración como Bien de Interés Cultural y una Carta Arqueológica en curso de la que aún no se han presentado resultados; Carmona, donde se mantienen unas Normas Subsidiarias aprobadas en 1983 y cuya 
Carta Arqueológica estuvo concebida más como un documento de investigación que para la gestión del Patrimonio Arqueológico; y Estepa, cuyas Normas Subsidiarias, aprobadas en 1988, recogen medidas de protección sólo para una parte del casco histórico y aún no ha desarrollado planeamiento de protección para el Conjunto Histórico, declarado en 1965.

2. Otra cuestión es el tratamiento otorgado al Patrimonio Arqueológico en los documentos urbanísticos. En este capítulo no es posible hablar de homogeneidad, se dan casi tantas variantes como textos se analizaron.

Así, los yacimientos arqueológicos se mueven entre unas determinaciones de protección muy consistentes, basadas en el análisis histórico-urbanístico del centro histórico realizado desde las cartas arqueológicas -Lebrija y, de otro modo, Priego de Córdoba- produciéndose, por consiguiente, un documento muy eficaz no sólo para la protección del Patrimonio Arqueológico sino también para su gestión ya que, en ambos casos, el planeamiento general asume e incorpora las conclusiones de aquellos documentos. Sin embargo, no ha sido así hasta ahora en Úbeda donde el interesante documento arqueológico conseguido, al no haber sido aún asumido por el Municipio, mantiene un carácter puramente informativo.

Los planes generales de Almería y Jaén, en cambio, son los documentos de carácter general que más desarrollan por sí mismos medidas de protección para el yacimiento urbano. Ambos se basan en trabajos de campo, no exactamente cartas arqueológicas tal y como las concebimos ahora, que quizás necesitarían una mayor concreción, como ha puesto de manifiesto en Jaén el ulterior hallazgo de un enorme enclave arqueológico, Marroquíes Bajos, en la zona de expansión de la ciudad.

En otros casos asistimos a la práctica negación del yacimiento arqueológico, como sucede en el PGOU de Jerez, donde las únicas medidas de protección planteadas para al Patrimonio Arqueológico se basan en su consideración como elemento arquitectónico -las murallas de la ciudad-, según explicamos más arriba.

En una situación intermedia se encontraría el PGOU de Guadix, cuya voluntad de proteger el Patrimonio Arqueológico se ve mediatizada por un texto puramente descriptivo sobre los resultados de excavaciones arqueológicas realizadas en el casco urbano, obviando el análisis arqueológico y del urbanismo histórico y, en consecuencia, desarrollando muy escasamente las medidas de protección y casi nada las de gestión. $O$ también el PGOU de Huelva, del que es más difícil adivinar cuál fue su voluntad habida cuenta del uso que se propone para los suelos donde se encuentran los yacimientos arqueológicos más significativos de la ciudad, alguno de ellos referencia de primer orden para la Protohistoria del occidente europeo.

Por último, se dan casos como el del PGOU de Vélez Málaga -cuyo Texto Refundido fue aprobado en 1996-, remitiendo las medidas de protección de yacimientos arqueológicos en Suelo Urbano a la adopción de soluciones particulares y específicas, a desarrollar en el Plan Especial en redacción.

Esto en cuanto a los documentos más recientes, claro. Pero si nos remitimos a las ciudades donde el planeamiento es anterior a la segunda mitad de los años 90, el tratamiento del Patrimonio Arqueológico prácticamente no va más allá de relacionar los enclaves conocidos en un catálogo donde, en el mejor de los casos, se especifican las obras que en ellos pueden ejecutarse -Almuñécar- o la posibilidad de realizar intervenciones arqueológicas previas -Carmona-; o no se dice absolutamente nada: Cuevas del Almanzora o Estepa.

Andújar representa la excepción en este grupo: su Plan General recoge una zonificación del Conjunto Histórico bajo tres niveles de protección y ello implica, cuando menos, la obligatoriedad de realizar actuaciones arqueológicas previas a los movimientos de tierra. 
Otras veces se han planteado medidas concretas, como la obligación de acometer excavaciones arqueológicas en los yacimientos así delimitados. Pero éstas atienden a los sitios arqueológicos del Término Municipal más que al Conjunto Histórico propiamente dicho, cuya gestión urbanística, por otra parte, suele resolverse mediante una única ordenanza. En esta situación se hallan las Normas Subsidiaras de Loja y de Niebla.

3. También pueden hacerse algunas observaciones sobre el tratamiento otorgado al Patrimonio Arqueológico en los documentos que conforman los expedientes de declaración de conjuntos históricos. Es interesante constatar que en muchos de ellos se realiza un análisis paisajístico que a veces trasciende el paisaje urbano propiamente dicho para abarcar el territorio inmediato a la ciudad, caso de la propuesta de declaración como BIC del Conjunto Histórico de Arcos de la Frontera donde, por otra parte, el yacimiento arqueológico no existe para el Plan General y, lo que es peor, tampoco para el Plan Especial.

El Patrimonio Arqueológico no goza nunca de esa atención, ni siquiera en lugares donde consta la existencia de restos de entidad inmediatos al ámbito declarado o incluidos parcial o totalmente en él: Tarifa, Montoro o Almuñécar, por ejemplo. Lugares en los que se plantea desde el documento urbanístico la posibilidad de poner en valor determinados elementos arqueológicos, o bien simplemente se están mostrando al público desde mucho tiempo antes, dándose la paradoja de que aquello que -aún trascendiendo su significado puramente cultural- se vende como imagen y puede representar un motivo de atracción y una fuente de ingresos para el municipio no se encuentra convenientemente tratado en el principal instrumento de ordenación del territorio.

En relación con el apartado anterior, es necesario reflexionar también sobre el estado actual del conocimiento del Patrimonio Arqueológico en los centros históricos escogidos. Debemos distinguir varios grupos:

a) Ciudades que poseen cartas arqueológicas finalizadas: Priego de Córdoba, Niebla, Úbeda, Carmona y Lebrija ${ }^{25}$. Los análisis histórico-arqueológicos de los conjuntos han sido extensos y exhaustivos y el conocimiento sobre su desarrollo histórico es, en consecuencia, bastante fiable.

El conocimiento de partida del yacimiento arqueológico era superior en Priego, Niebla y Carmona, pero ello no condujo a la redacción de documentos de mayor entidad. Más bien al contrario: la escasez de datos arqueológicos sobre los yacimientos urbanos de Úbeda y Lebrija obligó a profundizar en otros aspectos históricos y urbanísticos, produciendo documentos con una base teórico-metodológica más amplia y mayor contenido analítico. $Y$ aunque las soluciones para la protección del Patrimonio Arqueológico sean similares en su forma en todos los casos, no sucede así respecto a sus propuestas para la gestión urbanística y patrimonial.

b) Ciudades donde se han realizado intervenciones arqueológicas constantes desde el año 1985. En realidad son todas las estudiadas a excepción de Vélez Rubio, Arcos de la Frontera, Tarifa y Vélez Málaga.

Pero existe una gran diferencia entre el número y las características de las intervenciones, muy relacionada con las dimensiones de los cascos históricos y las dinámicas de sustitución inmobiliaria; en este sentido no podrían compararse, por ejemplo, Almería y Loja, o Ronda y Niebla. Entonces, trataremos ahora las ciudades donde las excavaciones han sido más numerosas en función de los

25 La Carta Arqueológica de Guadix ha sido recientemente publicada por la Consejería de Cultura, pero en el curso del trabajo no pude examinar tal documento. 
dos parámetros citados: las dimensiones del Conjunto Histórico y el nivel, presumible, de sustitución inmobiliaria 26.

Digamos que los cascos históricos que ostentan el mayor número de actuaciones arqueológicas son, como es lógico suponer, las tres capitales de provincia: de Almería se han publicado 19 excavaciones en el Anuario..., de Huelva, 26, y destaca Jaén donde sólo en Marroquíes Bajos se realizaron noventa y dos intervenciones entre 1995 y 1999 (ZAFRA DE LA TORRE, Narciso; HORNOS MATA, Francisca; CASTRO LÓPEZ, Marcelo, 1999) ${ }^{27}$.

Pero en dos centros básicos también se han realizado numerosas excavaciones: Carmona, alrededor de 100, y Priego de Córdoba que cita en su Carta Arqueológica hasta 80.

Sorprenden por su número, en relación a las dimensiones de los conjuntos históricos, las 17 intervenciones arqueológicas publicadas para la ciudad de Niebla ${ }^{28}$ y las II realizadas en Estepa ${ }^{29}$.

Si consideramos que en Jaén las excavaciones en Marroquíes Bajos superan con creces las ejecutadas en el Conjunto Histórico, podemos concluir que son tres centros básicos - Carmona, Priego de Córdoba y, a una considerable distancia, Estepa- junto a una ciudad cabecera municipal-Niebla- los lugares que, con diferencia, cuentan con más excavaciones arqueológicas ${ }^{30}$. c) Ciudades donde las intervenciones arqueológicas han sido escasas o inexistentes. En este capítulo parece necesario establecer algunos matices.

Como dijimos al principio, hay cinco ciudades donde no encontramos noticias sobre excavaciones: tres cabeceras municipales -Cuevas del Almanzora, Vélez Rubio y Tarifa- y dos centros intermedios: Arcos de la Frontera y Vélez Málaga.

En este caso, destaca la importancia patrimonial de las dos localidades gaditanas y la escasa consideración hacia su Patrimonio Arqueológico, que si en Arcos podría tener alguna justificación en base a su configuración geomorfológica, no encuentra excusa en el caso del Conjunto Histórico de Tarifa.

En cuanto a ciudades donde las intervenciones realizadas, a pesar de su escasez, justifican sobradamente la necesidad de elaborar una carta arqueológica que sistematice el yacimiento urbano destacan Jerez de la Frontera, Montoro, Almuñécar, Loja, Andújar, Ronda y Estepa ${ }^{3 !}$.

Junto a ciudades de la entidad patrimonial evidente de Arcos de la Frontera, Tarifa y Andújar, otras, como Cuevas del Almanzora que sólo cuenta una intervención arqueológica en su castillo, o Vélez Málaga, en cuyo casco histórico no conocemos ninguna excavación, deberían tomarse en consideración a la hora

26 El cual puede presuponerse a partir de las determinaciones de los documentos urbanísticos y en ocasiones se indica en los informes de diagnóstico de los Conjuntos Históricos.

27 Según los autores citados, entre 1995 y 1999 se realizaron 92 intervenciones arqueológicas, repartidas como sigue: Suelo Residencial Programado no 4: 50; Suelo Urbanizable No Programado: 5; Suelo Urbano, U. A. $n^{\circ} 23: 35$ y Suelo Urbano, U. A. $n^{\circ} 25: 2$. En la serie del Anuario... se citan también 50 intervenciones en el Conjunto Histórico.

28 Se recogen todas las excavaciones realizadas a lo largo del siglo $X X$.

29 Quiero recordar que estos datos se basan exclusivamente en el examen de la publicación de la Consejería de Cultura, Anuario Arqueológico de Andalucía, por lo que es muy posible que el número de excavaciones sea mayor en todos los casos. Una breve reseña de estas intervenciones arqueológicas se encuentra en el grueso del trabajo, en cada uno de los epígrafes correspondientes a cada ciudad.

30 Creo que estas cifras, con todas las reservas de no ser absolutas, podrían obedecer también a la gestión provincial de la propia Consejería de Cultura en cuanto al establecimiento de cautelas en las distintas ciudades andaluzas, sobre todo en momentos anteriores a la adopción generalizada de medidas de protección de carácter urbanístico.

31 Según información recabada en el Servicio de Protección de la Dirección General de Bienes Culturales, para todas las ciudades citadas —excepto Andújar y Estepa - ya se están elaborando cartas arqueológicas. 
de establecer prioridades para iniciar nuevas actuaciones arqueológicas. Quizás se pudieran obtener tan buenos resultados como en Lebrija, donde una vez que han empezado a aplicarse las determinaciones de protección del nuevo Plan General de Ordenación Urbana, el yacimiento bajo suelo urbano emerge con sorprendentes resultados.

4. Y, en relación directa con estas cuestiones debo, por último, citar los escasos ejemplos de elementos arqueológicos conservados y/o integrados en edificios y otras construcciones, sobre todo en relación con el volumen de intervenciones arqueológicas realizadas.

En este sentido, destaca el tramo de la muralla medieval conservado en Almería, primer exponente en la ciudad de una actividad de estas características habida cuenta de que la intervención fue realizada en 1985.

En el resto de las ciudades estudiadas tenemos pocos ejemplos. Algunas actuaciones de estas características se han llevado a cabo en Carmona, bien manteniendo los restos visitables (foso defensivo en la Puerta de SeviIla, estructuras romanas de la Puerta de Córdoba, estructura hipogea en el Paseo del Estatuto) o bien conservándolos bajo las nuevas construcciones (restos de una basílica y enterramientos asociados cisternas y pozos de la ciudad romana), aunque dado el volumen de intervenciones arqueológicas en la ciudad representan una mínima parte de aquellas. En Lebrija se está desarrollando actualmente el proyecto de conservación y puesta en valor de una calle y estructuras domésticas de la ciudad romana, que se integrarán en un edificio de uso público.

En el orden de los proyectos a ejecutar, destacamos la parcela dentro del yacimiento de Marroquíes Bajos (Jaén) que se ha reservado para la excavación, interpretación y exposición de los restos que se conserven (HORNOS MATA, Francisca; ZAFRA DE LA TORRE, Narciso; CASTRO LÓPEZ, Marcelo, 2000: 105 a 108); así como la propuesta del Plan Especial de la Alcazaba de Guadix, a desarrollar mediante el Programa Regional de Espacios Públi- cos, para integrar en un parque arqueológico los restos de estas características.

En resumen, de lo expuesto en los anteriores epígrafes, merecería la pena destacar algunas ideas fundamentales:

1. Se constata la existencia de yacimientos arqueológicos subyacentes y restos arqueológicos emergentes en todas las ciudades donde se realizaron intervenciones arqueológicas, y éste es un hecho que no puede ser ignorado por los instrumentos urbanísticos y de ordenación del territorio.

2. Entonces ipor qué cuesta tanto trabajo admitir su existencia como otro aspecto de la ciudad a considerar?, ipor qué no se reconoce la necesidad, y la ventaja, de gestionar los sitios arqueológicos también bajo criterios urbanísticos? Es decir, criterios urbanísticos que, partiendo de los principios legales en materia de Patrimonio Histórico y de un método de análisis histórico-arqueológico, valoren la magnitud de los yacimientos y admitan que para ordenar los suelos así considerados es necesario también contar con el concurso de otros profesionales: las/los arqueólogas/os.

3. Por supuesto que ello exigirá también por nuestra parte un esfuerzo de adaptación y aprendizaje de otras disciplinas porque deberemos asumir nuevas exigencias profesionales que trascienden el ámbito de la investigación histórica, y la formación arqueológica tradicional, hacia lo que llamaré la gestión integral de los yacimientos arqueológicos.

4. Desde esta perspectiva podrían vislumbrarse nuevos modos para la gestión del Patrimonio Arqueológico, superando la excavación indiscriminada de yacimientos en suelo urbano que no suele ir más allá de la reiterada constatación de secuencias históricas y produce un conocimiento acumulativo que, en la mayor parte de los casos, no se desarrolla en posteriores síntesis sobre la evolución histórica de las ciudades ni se plasma en la adopción de medidas de conservación y revalorización de los restos arqueológicos. 
Además, como se ha demostrado ya en algunas ciudades andaluzas, se agota el yacimiento con intervenciones cuya metodología y resultados ponen claramente en crisis la excavación arqueológica como único sistema para la protección e investigación de yacimientos en suelo urbano ${ }^{32}$.

5. En este sentido se muestran como una solución eficaz las Cartas Arqueológicas, cuyos resultados y propuestas para la gestión no proceden exclusivamente del conocimiento histórico-arqueológico de la ciudad, sino también del análisis de otras variables y elementos donde lo urbanístico juega un papel primordial.

Junto a ello, debemos tener en cuenta que estos documentos se producen mediante convenio, o cualquier otro modo de acuerdo, entre la Consejería de Cultura y los ayuntamientos, de tal modo que la actividad arqueológica -no exclusivamente excavación arqueológica-, al contar con la implicación y/o promoción más o menos directa de los poderes locales, suele abandonar ese limbo extraño donde se sitúa respecto a la mayoría de los ciudadanos.

6. La finalidad última de las cartas arqueológicas debe ser la protección, conservación y revalorización de restos arqueológicos. Es aquí donde se producen a menudo las grandes fricciones entre el Urbanismo y el Patrimonio Arqueológico como se ha demostrado sobradamente, por ejemplo, en Marroquíes Bajos (Jaén) o en la ciudad de Huelva. Y, en este sentido, las cartas deben aportar datos suficientes para determinar ámbitos y niveles de protección, pero también han de plantear propuestas de conservación.

Se trata, más allá de centrar la cuestión exclusivamente en la posible existencia o no de restos arqueológicos -lo que en ocasiones implicaría el dominio de artes adivi- natorias por los arqueólogos- de gestionar la conservación, introduciendo respuestas de escala general a cuestiones básicas de preservación: conocidos con cierta precisión diferentes ámbitos urbanos en las ciudades antiguas, será posible avanzar propuestas de conservación introduciendo en la ordenación del suelo indicadores en este sentido. Propuestas que irán desde la imposibilidad de afectar al yacimiento subyacente, ni siquiera con excavaciones arqueológicas, hasta la posible destrucción de los restos una vez documentados, pasando por la integración de elementos y/o estructuras en las nuevas construcciones, o bien previendo el cambio de uso del suelo en determinados ámbitos y condiciones.

7. Es decir -y trascendemos desde la esfera puramente arqueológica hacia la urbanística-, el análisis arqueológico debe tomar en consideración las determinaciones de ordenación del instrumento de planeamiento cuando aquél se realice de modo independiente, o sea cuando la Carta Arqueológica no vaya simultánea a la modificación, revisión o nueva formulación de un documento urbanístico. Pero cuando su origen sea la redacción o desarrollo de nuevos planeamientos, el Patrimonio Arqueológico ha de contar desde el principio como un elemento más en el diseño de la ciudad. Y no sólo para establecer áreas de protección sino para ser dignamente conservado e integrado, en la medida de lo posible, en la ciudad actual.

8. Y la conservación, como dijimos antes, no siempre ha de pasar por la excavación previa. Y la integración, obviamente, no puede ser extensiva. Por ello, los arqueólogos, desde el conocimiento de las ciudades antiguas y empleando técnicas y análisis históricos y arqueológicos, debemos marcar las pautas de la gestión patrimonial, y por consiguiente urbanística, de los suelos que albergan yacimientos arqueológicos.

32 Así ha sido constatado mediante el análisis de las intervenciones arqueológicas realizadas en los últimos veinte años en la ciudad de Córdoba con motivo de la redacción del nuevo Plan General de Ordenación Urbana. Lo mismo podría decirse seguramente para la ciudad de Sevilla si se realizara un trabajo de estas características. 


\section{BIBLIOGRAFÍA}

AYUNTAMIENTO DE JEREZ, CÁDIZ (1998): Texto Refundido: Jerez, Plan General Municipal de Ordenación Urbana. Versión en CD-ROM. Junta de Andalucía y Ayuntamiento de Jerez. Sevilla.

AYUNTAMIENTO DE JEREZ, CÁDIZ (1998): Plan especial de Reforma Interior Belén-Benavente, aprobado definitivamente el 29 de mayo de 1998. BOP de 3 de julio de 1998.

AYUNTAMIENTO DE LEBRIJA, SEVILLA (200I): Plan General de Ordenación Urbana y Catálogo. Ordenanzas en el BOP de 12 de junio de 2001 .

AYUNTAMIENTO DE ÚBEDA, JAÉN (1996): Plan General de Ordenación Urbana. BOP de 31 de diciembre de 1996.

AYUNTAMIENTO DE ÚBEDA, JAÉN (1997): Plan Especial de Protección del Conjunto Histórico, adaptación a Revisión P.G.O.U 1996. BOP de 27 de febrero de 1997.

CARO BELLIDO, Antonio; ACOSTA MARTíNEZ, Pilar; ESCACENA CARRASCO, José L. (1987): "Informe sobre la prospección arqueológica con sondeo estratigráfico en el solar de la calle Alcazaba (Lebrija, Sevilla)", Anuario Arqueológico de Andalucía 86. III. Junta de Andalucía. Sevilla.

CONSEJERÍA DE OBRAS PÚBLICAS Y TRANSPORTES (200I): Análisis urbanístico de centros históricos de Andalucía. Ciudades medias y pequeñas. Junta de Andalucía. Sevilla.
FERIA TORIBIO, José Ma; MIURA ANDRADES, José Ma; RUIZ RECCO, Francisco J. (dirs.) (2002): Redes de Centros Históricos de Andalucía, Junta de Andalucía, Sevilla.

HORNOS MATA, Francisca; ZAFRA DE LA TORRE, Narciso; CASTRO LÓPEZ, Marcelo (2000): "Perspectivas, itinerarios e intersecciones: Experiencias y propuestas de apropiación cultural de Marroquíes Bajos, Jaén", Trabajos de Prehistoria, 57, $n^{\circ} 2$.

RAYA PRAENA, Inmaculada; BURGOS JUÁREZ, Antonio; FERNÁNDEZ-ARAGÓN SÁNCHEZ, Ignacio; LIZCANO PRESTEL, Rafael; PÉREZ BAREAS, Cristóbal (2003): Carta Arqueológica Municipal. Guadix, Junta de Andalucía. Consejería de Cultura. Sevilla.

RODRÍGUEZ DE GUZMÁN SÁNCHEZ, Sandra; GONZÁLEZ-CAMPOS BAEZA, Yolanda (2002).: "La tutela del Patrimonio Histórico a través de las Cartas Arqueológicas municipales", Boletín IAPH, $\mathrm{n}^{\circ}$ 38, marzo 2002, Junta de Andalucía. Consejería de Cultura. Sevilla.

RODRÍGUEZ TEMIÑO, Ignacio; RODRÍGUEZ DE GUZMÁN SÁNCHEZ, Sandra (1997): "Excavaciones arqueológicas en Andalucía: 1984-1995.", Trabajos de Prehistoria, $54 \mathrm{n}^{\circ}$ ।.

SALVATIERRA CUENCA, Vicente; GARCÍA GRANADOS, Juan (2000): Úbeda, Carta de Riesgo Arqueológico, Junta de Andalucía. Jaén.

ZAFRA DE LA TORRE, Narciso; HORNOS MATA, Francisca; CASTRO LÓPEZ, Marcelo (1999): "Una macro-aldea en el origen del modo de vida campesino: marroquíes Bajos (Jaén) c. 2500-2000 ANE", Trabajos de Prehistoria, $56, n^{\circ} 1$. 